\title{
Profound Decreases in Dopamine Release in Striatum in Detoxified Alcoholics: Possible Orbitofrontal Involvement
}

\author{
Nora D. Volkow, ${ }^{1,2}$ Gene-Jack Wang, ${ }^{3}$ Frank Telang, ${ }^{2}$ Joanna S. Fowler, ${ }^{3}$ Jean Logan, ${ }^{3}$ Millard Jayne, ${ }^{2}$ Yeming Ma, ${ }^{2}$ \\ Kith Pradhan, ${ }^{4}$ and Christopher Wong ${ }^{3}$ \\ ${ }^{1}$ National Institute on Drug Abuse, Bethesda, Maryland 20892, 2Laboratory of Neuroimaging, National Institute on Alcohol Abuse and Alcoholism, \\ Bethesda, Maryland 20892, ${ }^{3}$ Medical Department, Brookhaven National Laboratory, Upton, New York 11973, and ${ }^{4}$ Department of Applied Mathematics, \\ State University of New York at Stony Brook, Stony Brook, New York 11794
}

The value of rewards (natural rewards and drugs) is associated with dopamine increases in the nucleus accumbens and varies as a function of context. The prefrontal cortex has been implicated in the context dependency of rewards and in the fixated high value that drugs have in addiction, although the mechanisms are not properly understood. Here we test the hypothesis that the prefrontal cortex regulates the value of rewards by modulating dopamine increases in nucleus accumbens and that this regulation is disrupted in addicted subjects. We used positron emission tomography to evaluate the activity of the prefrontal cortex (measuring brain glucose metabolism with $\left[{ }^{18} \mathrm{~F}\right]$ fluorodeoxyglucose) and dopamine increases (measured with $\left[{ }^{11} \mathrm{C}\right]$ raclopride, a $\mathrm{D}_{2} / \mathrm{D}_{3}$ receptor ligand with binding that is sensitive to endogenous dopamine) induced by the stimulant drug methylphenidate in 20 controls and 20 detoxified alcoholics, most of whom smoked. In all subjects, methylphenidate significantly increased dopamine in striatum. In ventral striatum (where the nucleus accumbens is located) and in putamen, dopamine increases were associated with the rewarding effects of methylphenidate (drug liking and high) and were profoundly attenuated in alcoholics ( 70 and $50 \%$ lower than controls, respectively). In controls, but not in alcoholics, metabolism in orbitofrontal cortex (region involved with salience attribution) was negatively associated with methylphenidate-induced dopamine increases in ventral striatum. These results are consistent with the hypothesis that the orbitofrontal cortex modulates the value of rewards by regulating the magnitude of dopamine increases in the ventral striatum and that disruption of this regulation may underlie the decreased sensitivity to rewards in addicted subjects.

Key words: PET; dopamine; alcohol; orbitofrontal cortex; ventral striatum; reward

\section{Introduction}

Increases in dopamine (DA) are linked with the reinforcing responses to substances of abuse including alcohol (Koob et al., 1998), but the mechanism(s) underlying addiction is much less clear. It is believed that chronic drug use results in adaptive changes in regions (circuits) modulated by DA that underlie the neurobiology of addiction (Robbins and Everitt, 2002; Nestler, 2004). Among these, the prefrontal cortex is increasingly being recognized as playing a central role in addiction (Jentsch and Taylor, 1999). Particularly relevant are prefrontal cortical efferents to the ventral tegmental area (VTA) and to the nucleus accumbens (NAc), which play a key role in regulating the firing pattern of DA cells and of DA release, respectively (Gariano and

\footnotetext{
Received July 25, 2007; revised 0ct. 2, 2007; accepted 0ct. 2, 2007.

This work was supported in part by the Intramural Research Program of the National Institutes of HealthNational Institute on Alcoholism and Alcohol Abuse, by the Department of Energy (Office of Biological and Environmental Research, contract DE-AC01-76CH00016), and by National Institute of Mental Health Grant MH66961-02. We thank Donald Warner for PET operations; David Schlyer and Michael Schueller for cyclotron operations; David Alexoff and Paul Vaska for quality control of PET measures; Colleen Shea, Lisa Muench, and Youwen Xu for radiotracer synthesis; Pauline Carter for nursing care; Karen Apelskog for protocol coordination; and Linda Thomas for editorial assistance.

Correspondence should be addressed to Dr. Nora D. Volkow, National Institute on Drug Abuse, 6001 Executive Boulevard, Room 5274, Bethesda, MD 20892. E-mail: nvolkow@nida.nih.gov. DOI:10.1523/JNEUROSCI.3371-07.2007

Copyright $\odot 2007$ Society for Neuroscience $\quad 0270-6474 / 07 / 2712700-07 \$ 15.00 / 0$
}

Groves, 1988; Murase et al., 1993). Indeed, preclinical studies have documented changes in this pathway with chronic drug exposure, which have been hypothesized to underlie the loss of control over drug intake that characterizes addiction (White et al., 1995; Kalivas, 2004).

The purpose of this study was to evaluate the regulation of brain DA activity by the prefrontal cortex in alcoholism. To assess brain DA activity, we used positron emission tomography (PET) and $\left[{ }^{11} \mathrm{C}\right.$ ]raclopride $\left(\mathrm{DA} \mathrm{D}_{2} / \mathrm{D}_{3}\right.$ receptor radioligand with binding that is sensitive to competition by endogenous DA) (Volkow et al., 1994a) before and after challenge with intravenous methylphenidate (MP) and compared the responses between 20 detoxified alcoholics and 20 healthy controls. We used MP as the pharmacological challenge because it increases DA by blocking DA transporters (DATs) and thus allows for the indirect assessment of DA cell activity (Volkow et al., 2002). To evaluate the activity of the prefrontal cortex, we measured regional brain glucose metabolism, which serves as a marker of brain function (Sokoloff et al., 1977), using PET and $\left[{ }^{18} \mathrm{~F}\right]$ fluorodeoxyglucose (FDG). Our working hypotheses were that in alcoholic subjects, the regulation of DA brain activity by the prefrontal cortex would be disrupted and that they would have decreased DA activity. Also because MP-induced striatal DA increases are associated with its rewarding effects (Volkow et al., 1999), we also hypoth- 
Table 1. Demographic and clinical characteristics of controls and alcoholic subjects

\begin{tabular}{lll}
\hline & Original groups & \\
\cline { 2 - 3 } & Alcoholic subjects $(n=20)$ & Control subjects $(n=20)$ \\
\hline Age & $41 \pm 6$ & $41 \pm 6$ \\
Education (years) & $13 \pm 2$ & $14 \pm 2$ \\
Ethnicity & 16 Caucasians & 18 Caucasians \\
& 2 Hispanics & 2 Hispanics \\
Age of alcohol use onset & 2 Native Americans & \\
Age at heavy drinking & $13 \pm 3$ & \\
Years of alcohol abuse & $18 \pm 6$ & \\
Beer equivalents per day & $23 \pm 8$ & \\
Days since last alcohol & $16 \pm 6$ & 3 \\
Smokers & $79 \pm 38$ (range, 30-164) & \\
\hline
\end{tabular}

esized that reduced DA release in alcoholics would lead to a blunting of the subjective perception of the pleasurable effects of MP.

\section{Materials and Methods}

Subjects. Twenty male alcoholic subjects and 20 male healthy controls were studied. Alcoholics were recruited from therapeutic communities and advertisements. Table 1 provides demographic and clinical characteristics of subjects. At least two clinicians interviewed the patients to ensure that they met Diagnostic and Statistical Manual of Mental Disorders (DSM), fourth revision, diagnostic criteria for alcoholism, with a semistructured standardized interview using DSM criteria. Inclusion criteria also required that they had a first-degree relative who was an alcoholic. Subjects were excluded if they had history of substance abuse or addiction (other than alcohol and nicotine). Exclusion criteria also included history of psychiatric disease (other than alcohol dependence) or neurological disease, medical conditions that may alter cerebral function (i.e., cardiovascular, endocrinological, oncological, or autoimmune diseases), current use of prescribed or over-the-counter medications, and/or head trauma with loss of consciousness of $>30 \mathrm{~min}$. All subjects had Hamilton anxiety (Hamilton, 1959) and Hamilton depression (Hamilton, 1960) scores $<19$ and had to have refrained from drinking alcohol at least $30 \mathrm{~d}$ before the study. Controls were recruited from advertisements in local newspapers; exclusion criteria other than allowance for alcohol dependence or abuse were the same as for alcoholic subjects. In addition, control subjects were excluded if they had a family history of alcoholism. All subjects had a physical, psychiatric, and neurological examination. Drug screens were done on the days of the PET studies to exclude the use of psychoactive drugs. Subjects were instructed to discontinue any over-the-counter medication 2 weeks before the PET scan, and controls were instructed to refrain from drinking alcohol the week before the PET scan. Food and beverages (except for water) were discontinued at least $4 \mathrm{~h}$ before and cigarettes were discontinued for at least $2 \mathrm{~h}$ before the study. This study was approved by the Institutional Review Board at Brookhaven National Laboratory, and written informed consent was obtained from all subjects.

Behavioral and cardiovascular measures. Subjective ratings (1-10) for drug effects were recorded before and 27 min after placebo or MP administration (Wang et al., 1997). These self-reports of drug effects have been shown to be reliable and consistent across studies (Fischman and Foltin, 1991). Heart rate and blood pressure were monitored before and periodically after placebo or MP administration.

Scans. PET studies were done with a Siemens (Iselin, NJ) HR + tomograph (resolution, $4.5 \times 4.5 \times 4.5 \mathrm{~mm}$ full-width half-maximum) in three-dimensional mode. All subjects completed two scans done with $\left[{ }^{11} \mathrm{C}\right]$ raclopride, and 19 of the controls and 19 of the alcoholics completed a third scan done with FDG. The scans were completed over a $2 \mathrm{~d}$ period, and the order was randomized. Methods have been published for $\left[{ }^{11} \mathrm{C}\right]$ raclopride (Volkow et al., 1993a) and for FDG (Wang et al., 1993). For the $\left[{ }^{11} \mathrm{C}\right]$ raclopride scans, one of the two scans was done after intravenous placebo ( $3 \mathrm{cc}$ of saline), and the other was done after intravenous MP $(0.5 \mathrm{mg} / \mathrm{kg})$, which were given $1 \mathrm{~min}$ before $\left[{ }^{11} \mathrm{C}\right]$ raclopride injec- tion. The study was a single-blind crossover design. Dynamic scans were started immediately after injection of $4-10 \mathrm{mCi}$ of $\left[{ }^{11} \mathrm{C}\right]$ raclopride (specific activity, $0.5-1.5 \mathrm{Ci} / \mu \mathrm{M}$ at end of bombardment) and were obtained for a total of $54 \mathrm{~min}$. Arterial blood was obtained throughout the procedure to measure the concentration of unchanged $\left[{ }^{11} \mathrm{C}\right]$ raclopride in plasma as described previously (Volkow et al., 1993a). For FDG, the measures were done at baseline conditions (no stimulation), and a 20 min emission scan was started $35 \mathrm{~min}$ after injection of $4-6 \mathrm{mCi}$ of FDG, and arterial blood was used to measure FDG in plasma. During the uptake period, subjects remained in a supine position with their eyes open in a darkly lit room, and noise was kept to a minimum. Metabolic rates were computed using an extension of Sokoloff's model (Phelps et al., 1979).

Image analysis. For the $\left[{ }^{11} \mathrm{C}\right]$ raclopride images, regions of interest (ROIs) were obtained directly from the $\left[{ }^{11} \mathrm{C}\right]$ raclopride images as described previously (Volkow et al., 1994a). Briefly, we selected the ROI on summed images (dynamic images taken from 10 to $54 \mathrm{~min}$ ) that were resliced along the intercommisural plane from which we selected regions in caudate (CDT), putamen (PUT), ventral striatum (VS), and cerebellum. These regions were then projected to the dynamic scans to obtain concentrations of C-11 versus time, which were used to calculate the $K_{1}$ (transport constant from plasma to tissue) and the distribution volume (DV), which corresponds to the equilibrium measurement of the ratio of tissue concentration to plasma concentration in CDT, PUT, and VS using a graphical analysis technique for reversible systems (Logan et al., 1990). The ratio of the DV in striatum to that in cerebellum, which corresponds to $B_{\max }{ }^{\prime} / K_{\mathrm{d}}{ }^{\prime}+1\left(K_{\mathrm{d}}{ }^{\prime}\right.$ and $B_{\max }{ }^{\prime}$ are the effective in vivo constants in the presence of endogenous neurotransmitter and nonspecific binding), was used as an estimate of $\mathrm{D}_{2} / \mathrm{D}_{3}$ receptor availability (Logan et al., 1990). The effects of MP on $\left[{ }^{11} \mathrm{C}\right]$ raclopride binding were quantified as percentage change in $B_{\max }{ }^{\prime} / K_{\mathrm{d}}{ }^{\prime}$ from placebo (dependent variable).

For the metabolic images, we extracted ROI using an automated extraction method as described previously and sampled (1) a prioriidentified prefrontal regions [orbitofrontal cortex (OFC), cingulate gyrus (CG), dorsolateral prefrontal], because preclinical studies have shown that they regulate DA release; (2) striatal regions (CDT, PUT, VS), because these are main targets of DA terminals; (3) limbic regions (amygdala, hippocampus, insula), because they are also targets of DA terminals; and (4) thalamic, temporal, parietal, occipital, and cerebellar regions, which we treated as control regions (Volkow et al., 2006). Briefly, we first mapped the metabolic images into the MNI (Montreal Neurological Institute) standard brain space to eliminate variations across individuals' brains. To perform the ROI calculations, we produced a map that covered all the corresponding voxels for a given region following the coordinates in the Talairach Daemon software (Collins et al., 1995; Lancaster et al., 2000) into the FDG PET image.

Statistical analysis. The effects of $\mathrm{MP}$ on $K_{1}$ and on $\mathrm{D}_{2} / \mathrm{D}_{3}$ receptor availability $\left(B_{\max }{ }^{\prime} / K_{\mathrm{d}}{ }^{\prime}\right)$ and the differences between the groups at baseline and in response to MP were assessed with ANOVA with one between-subject factor (control vs alcoholics) and one within-subject factor (placebo vs MP). Post hoc $t$ tests were used to determine which of the conditions differed. To assess the association between MP-induced changes in $B_{\max }{ }^{\prime} / K_{\mathrm{d}}{ }^{\prime}$ (dependent variable) in CDT, PUT, and VS and regional brain metabolism, we performed Pearson product moment correlation analysis on the metabolic measures. To test the three main hypotheses of the study (1) that in controls but not in alcoholics metabolism in prefrontal regions [CG, OFC, and dorsolateral prefrontal cortex (DLPFC)] would be associated with MP-induced changes in $B_{\max }{ }^{\prime} / K_{\mathrm{d}}{ }^{\prime}$ (dependent variable), (2) that MP induced changes in $B_{\max }{ }^{\prime} / K_{\mathrm{d}}^{\prime}{ }^{\prime}$ would be smaller in alcoholics than controls, and (3) that changes in $B_{\max }{ }^{\prime} / K_{\mathrm{d}}{ }^{\prime}$ in VS would be associated with the rewarding effects of MP and thus ratings for "drug liking" and "high" would be lower in alcoholics than controls, we set the level of significance at $p<0.05$. For the exploratory analysis to evaluate correlations between changes in $B_{\max }{ }^{\prime} / K_{\mathrm{d}}{ }^{\prime}$ (dependent variable) and metabolism in the 11 ROIs that were not a priori defined, we set significance at $p<0.005$. To corroborate that the correlations reflected regional activity rather than overall absolute metabolic activity, we also assessed the correlations on the normalized regional 
Table 2. Behavioral effects of intravenous MP in controls and alcoholic subjects and $F$ values for the factorial repeated ANOVA for the group, drug, and interaction effects

\begin{tabular}{|c|c|c|c|c|c|c|c|}
\hline & \multicolumn{2}{|c|}{ Control subjects } & \multicolumn{2}{|c|}{ Alcoholic subjects } & \multicolumn{3}{|l|}{ ANOVA } \\
\hline & Placebo & MP & Placebo & MP & Group & Drug & Interaction \\
\hline Feel drug & $1 \pm 1$ & $5 \pm 3$ & $1 \pm 0$ & $3 \pm 2$ & 0.03 & 0.0001 & 0.05 \\
\hline Anxiety & $2 \pm 1$ & $4 \pm 3$ & $3 \pm 3$ & $3 \pm 2$ & NS & 0.005 & 0.05 \\
\hline Happy & $6 \pm 2$ & $7 \pm 3$ & $8 \pm 2$ & $6 \pm 2$ & NS & 0.05 & 0.02 \\
\hline High & $1 \pm 1$ & $6 \pm 3$ & $1 \pm 0$ & $3 \pm 2$ & 0.001 & 0.0001 & 0.002 \\
\hline Mood & $7 \pm 2$ & $8 \pm 2$ & $7 \pm 2$ & $6 \pm 2$ & NS & NS & 0.03 \\
\hline Restlessness & $1 \pm 1$ & $5 \pm 3$ & $2 \pm 2$ & $4 \pm 3$ & NS & 0.0001 & NS \\
\hline Stimulated & $3 \pm 2$ & $7 \pm 3$ & $4 \pm 3$ & $5 \pm 3$ & NS & 0.0002 & 0.003 \\
\hline Drug good & $1 \pm 0$ & $6 \pm 4$ & $1 \pm 0$ & $3 \pm 3$ & 0.03 & 0.0001 & 0.02 \\
\hline Drug liking & $2 \pm 1$ & $6 \pm 3$ & $2 \pm 2$ & $4 \pm 3$ & 0.05 & 0.0001 & 0.05 \\
\hline Drug disliking & $1 \pm 1$ & $4 \pm 3$ & $2 \pm 2$ & $7 \pm 3$ & 0.002 & 0.0001 & 0.05 \\
\hline Desire alcohol & $1 \pm 0$ & $2 \pm 1$ & $1 \pm 0$ & $3 \pm 3$ & NS & 0.005 & NS \\
\hline Desire tobacco & $1 \pm 0$ & $1 \pm 1$ & $3 \pm 3$ & $6 \pm 4$ & 0.0001 & 0.0001 & 0.002 \\
\hline
\end{tabular}

Values correspond to means and SDs for the measures obtained 25-30 min after placebo or MP administration.

metabolic measures (regional metabolism/ whole-brain absolute metabolism). Differences on the correlations between the groups were tested using an overall test of coincidences for the regressions.

Because in previous studies we have seen a correlation between baseline measures of $\mathrm{D}_{2} / \mathrm{D}_{3}$ receptor availability and prefrontal metabolism in cocaine and methamphetamine abusers (Volkow et al., 1993b, 2001), we also assessed these correlations to determine whether a similar association occurred in alcoholic subjects (significance was set at $p<0.05$ ).

\section{Results}

\section{Plasma concentrations of MP}

Plasma concentrations (in nanograms per millimeter) did not differ between controls and alcoholic subjects at $10 \mathrm{~min}$ (116 \pm 26 vs $107 \pm 16$, respectively), 30 $\min (85 \pm 25$ vs $76 \pm 12)$, or $45 \min (65 \pm$ 15 vs $59 \pm 11)$. The plasma MP concentration did not correlate with MP-induced changes in $B_{\max }{ }^{\prime} / K_{\mathrm{d}}{ }^{\prime}$.

\section{Behavioral responses to MP}

In both groups, MP significantly $(p<0.005)$ increased scores on self-reports for feel drug, high, restlessness, stimulated, drug good, drug liking, drug disliking, desire for alcohol, and desire for tobacco (Table 2). The interaction effect was significant for most of the self-reports of drug effects (except for restlessness and desire for alcohol) (Table 2). Post hoc $t$ tests revealed that MP effects were significantly larger in controls than in alcoholics for high $(p<0.003)$, stimulated ( $p<0.003)$, feel drug $(p<0.004)$, drug $\operatorname{good}(p<0.04)$, and drug liking $(p<0.04)$ and were greater in alcoholics for desire for tobacco $(p<0.002)$ and drug disliking $(p<0.05)$.

MP increased heart rate and systolic and diastolic blood pressure, and these effects did not differ between groups (data not shown).

\section{Measures of $\mathrm{DA} \mathrm{D}_{2} / \mathrm{D}_{3}$ receptor availability at baseline (placebo)}

At baseline, there were no differences in $K_{1}$ between groups in cerebellum, CDT, PUT, or VS (Table 3). In contrast, $\mathrm{D}_{2} / \mathrm{D}_{3}$ receptor availability $\left(B_{\max }{ }^{\prime} / K_{\mathrm{d}}{ }^{\prime}\right)$ showed a significant group effect in VS $(p<0.007)$ but no differences in CDT and PUT. Post hoc $t$ test showed that VS $D_{2} / D_{3}$ receptor availability was significantly lower in alcoholics $(p<0.05)$ (Table 3$)$.

\section{Measures of $\mathrm{DA} \mathrm{D}_{2} / \mathrm{D}_{3}$ receptor availability after MP (DA changes)}

ANOVA on the $K_{1}$ measures revealed that neither the drug nor the interaction effects were significant in CDT, PUT, VS, or cerebellum, which indicates that MP did not change radiotracer delivery and that there were no differences between groups ( $\mathrm{Ta}$ ble 3).

MP decreased $B_{\max }{ }^{\prime} / K_{\mathrm{d}}{ }^{\prime}$, and the ANOVA revealed a significant drug effect in CDT $(F=19 ; p<0.001)$, PUT $(F=54 ; p<$ $0.0001)$, and VS $(F=41 ; p<0.001)$, which indicates that $B_{\max }{ }^{\prime} /$ $K_{\mathrm{d}}{ }^{\prime}$ was significantly reduced by MP in both groups (see Fig. 2, Table 3). The interaction effect was significant for PUT $(F=5.5$; $p<0.03)$ and VS $(F=13 ; p<0.001)$, which indicates that the responses in these regions differed between groups. The post hoc $t$ test revealed that the reductions with MP were significantly smaller in alcoholics in PUT (controls, $21 \%$ vs alcoholics, $11 \%$; $p<0.03$ ) and VS (controls, 27\% vs alcoholics, $8 \%$; $p<0.002$ ) (Fig. 1, Table 3).

To assess whether the smaller changes in $B_{\max }{ }^{\prime} / K_{\mathrm{d}}{ }^{\prime}$ (PUT and VS) in alcoholics than in controls reflected their greater number of smokers, we compared the smokers from the nonsmokers sep- 


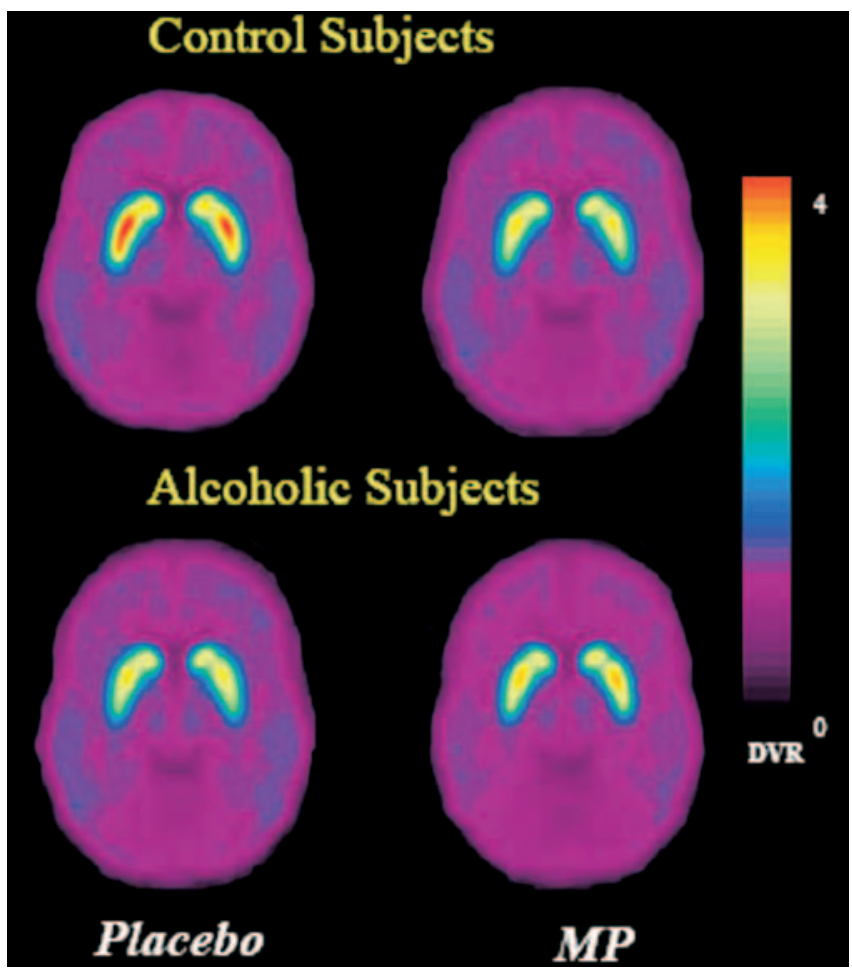

Figure 1. Average for the DV ratio (DVR) images for $\left[{ }^{11} \mathrm{C}\right]$ raclopride for the controls $(n=20)$ and the alcoholics $(n=20)$ at the level of striatum after placebo and after MP. Note the decrease in specific binding (DV ratios) with MP and the attenuated response to MP in alcoholic subjects compared with the controls.

arately for each group and showed the following: (1) the controls who smoked $(n=3)$ had similar changes than those who did not $(n=17)$ in PUT (20 vs $21 \%$, respectively) and VS ( 35 vs $26 \%$, respectively); and (2) the alcoholics who smoked $(n=16)$ had similar changes than those who did not $(n=4)$ in PUT (11 vs $12 \%$, respectively) and VS (8 vs 6\%, respectively).

Although the samples are too small to yield conclusive results, in none of these comparisons were the changes in $B_{\max }{ }^{\prime} / K_{\mathrm{d}}{ }^{\prime}$ smaller in smokers, which suggests that the smaller changes in alcoholics are not just attributable to smoking.

Regional brain glucose metabolism and correlation with MPinduced changes in $B_{\max }{ }^{\prime} / K_{\mathrm{d}}{ }^{\prime}$ and with baseline measures of $D_{2}$ receptor availability

Neither whole-brain (controls, $36.4 \pm 4 \mu \mathrm{mol} / 100 \mathrm{~g} / \mathrm{min}$; alcoholics, $35.0 \pm 4 \mu \mathrm{mol} / 100 \mathrm{~g} / \mathrm{min}$ ) nor regional metabolism differed between groups (data not shown).

In controls, MP-induced changes in $B_{\max }{ }^{\prime} / K_{\mathrm{d}}{ }^{\prime}$ in VS were negatively correlated with metabolism in OFC [Brodmann's area (BA) 11: $r=0.62, p<0.006$; BA 47: $r=0.60, p<0.008$ ], DLPFC (BA 9: $r=0.59, p<0.01$ ), CG (BA 32: $r=0.50 p<0.04$; BA 24: $r=0.52, p<0.03)$, and insula $(r=0.63$; $p<0.005)$. (Fig. 2). $B_{\max }{ }^{\prime} / K_{\mathrm{d}}{ }^{\prime}$ changes in CDT and PUT were only correlated with metabolism in CG $(r>0.51 ; p<0.03)$. In alcoholics, the correlations between MP-induced changes in $B_{\max }{ }^{\prime} / K_{\mathrm{d}}{ }^{\prime}$ and regional metabolism were not significant (Fig. 2). Comparison of the regression slopes between the groups revealed that correlations differed significantly in OFC $(z=2.3 ; p<0.05)$, DLPFC $(z=2.2$; $p<0.05)$, CG $(z=2.2 ; p<0.05)$, and insula $(z=2.6 ; p<0.01)$.

The correlations with the normalized metabolic measures (region/whole-brain metabolism) was significant only for the changes between $B_{\max }{ }^{\prime} / K_{\mathrm{d}}{ }^{\prime}$ in VS and OFC $(r=0.62 ; p<0.006)$ in controls but not in alcoholics (Fig. 3). This correlation differed significantly between the groups $(z=2.1 ; p<0.05)$.

The correlations with baseline $B_{\max }{ }^{\prime} / K_{\mathrm{d}}{ }^{\prime}\left(\mathrm{D}_{2}\right.$ receptor availability) and regional metabolism were significant for alcoholics but not controls in CG (CDT: $r=0.57, p<0.02$; PUT: $r=0.59$, $p<0.01$; VS: $r=0.57, p<0.02)$ and DLPFC (CDT: $r=0.52, p<$ 0.03; PUT: $r=0.52, p<0.03$; VS: $r=0.50, p<0.03)$

Correlation between MP-induced changes in $B_{\max }{ }^{\prime} / K_{\mathrm{d}}{ }^{\prime}$ and its behavioral effects and drinking and smoking histories Changes in $B_{\max }{ }^{\prime} / K_{\mathrm{d}}{ }^{\prime}$ in VS correlated with high $(r=0.40 ; p<$ $0.01)$, drug good $(r=0.33 ; p<0.05)$, happy $(r=0.33 ; p<0.05)$ restlessness $(r=0.38 ; p<0.02)$, and stimulated $(r=0.45 ; p<$ $0.005)$; in PUT with high $(r=0.32 ; p<0.05)$, drug good $(r=$ $0.34 ; p<0.05)$, and stimulated $(r=0.46 ; p<0.005)$; and in CDT with stimulated $(r=0.32 ; p<0.05)$.

Neither alcohol nor smoking histories correlated with changes in $B_{\max }{ }^{\prime} / K_{\mathrm{d}}{ }^{\prime}$ when all the alcoholics were included. However, when only the alcoholics who smoked were analyzed, there was a significant correlation between changes in $B_{\max }{ }^{\prime} / K_{\mathrm{d}}{ }^{\prime}$ and years of smoking (PUT: $r=0.73, p<0.002$ ) and age at smoking initiation (PUT: $r=0.63, p<0.009$; VS: $r=0.53, p<0.05$ ).

\section{Discussion}

Prefrontal regulation of MP-induced DA changes in controls but not in alcoholics

In controls, we show a negative association between absolute metabolic activity in prefrontal regions (OFC, CG, DLPFC) and MP-induced changes in $B_{\max }{ }^{\prime} / K_{\mathrm{d}}{ }^{\prime}$ (estimate of DA changes) in VS and PUT. Moreover, this correlation remained in the OFC after normalizing for whole-brain metabolic activity indicating that, at least in OFC, it is regionally specific. This finding is consistent with preclinical studies documenting prefrontal regulation of DA cells in VTA and of DA release in NAc (Gariano and Groves, 1988; Murase et al., 1993).

In contrast in alcoholics, metabolism in prefrontal regions was not correlated with DA changes (as assessed by changes in $\left.B_{\max }{ }^{\prime} / K_{\mathrm{d}}{ }^{\prime}\right)$. This suggests that in alcoholics, regulation of DA cell activity by prefrontal efferents is disrupted and that their decreased DA cell activity may represent loss of prefrontal regulation of DA mesolimbic pathways. One of the main inputs to DA cells in VTA is glutamatergic efferents from the prefrontal cortex (Carr and Sesack, 2000), and there is growing evidence that they play an important role in addiction (Kalivas and Volkow, 2005). Preclinical studies have also shown that the influence of the prefrontal cortex on behavior regulation decreases with chronic drug administration contributing to the loss of control in addiction (Homayoun and Moghaddam, 2006). Moreover, disruption of OFC (region involved with salience attribution, the disruption of which is associated with compulsive behaviors) and of CG (region involved with inhibitory control, the disruption of which is associated with impulsivity) is considered central to the process of addiction (Volkow et al., 2003).

The exploratory analysis revealed that in controls, DA changes in VS were also correlated with metabolism in insula. The insula is one of the cortical regions with the densest DA innervation (Gaspar et al., 1989), and a recent study reporting that damage to the right insula was linked with abrupt smoking cessation highlights its importance in addiction (Naqvi et al., 2007).

\section{Decreased DA release in alcoholic subjects}

In alcoholics, MP induced much smaller DA increases in VS and PUT than in controls. MP is a DAT blocker, and for a given level 
of DAT blockade, DA changes reflect the amount of spontaneous DA released (Volkow et al., 1999). Because the concentration of MP in plasma, which did not differ between groups, predicts the levels of DAT blockade (Volkow et al., 1998, 1999), the blunted response to MP suggests that alcoholics have lower DA release than controls. The decrements were most accentuated in VS (70\% lower than controls), which corroborates previous findings of reduced DA increases in VS after amphetamine in alcoholics (50\% lower than controls) (Martinez et al., 2005). These findings are also in agreement with preclinical studies showing profound reductions in DA cell firing (Diana et al., 1993; Bailey et al., 1998; Shen et al., 2007) in VTA and decreased DA in NAc (Weiss et al., 1996) after withdrawal from chronic alcohol. Decreased reactivity of the DA VTA-accumbens pathway in alcoholics could put them at risk to consume large amounts of alcohol to compensate for this deficit. Indeed, acute alcohol administration restores the activity of VTA DA cells in animals treated chronically with alcohol (Diana et al., 1996; Weiss et al., 1996).

Alcoholics also showed blunted MP-induced DA increases in PUT (47\% lower than in controls). This most likely reflects involvement of DA cells in substantia nigra, which project to PUT and are implicated in motor behavior. DA deficits in PUT could explain the greater vulnerability for extrapyramidal motor symptoms in alcoholics (Shen, 1984).

Previous studies in cocaine abusers also documented significant reductions in MP-induced DA increases (50\% lower than controls) (Volkow et al., 1997), which suggests that decreased DA cell activity may reflect a common abnormality in addiction.

\section{Reduced reinforcing responses to intravenous MP}

in alcoholics

Subjective rewarding responses to MP in alcoholics were lower than in controls. The fact that these subjective effects of MP were associated with DA increases in VS suggests that the blunted reinforcing responses to MP reflect decreased VTA DA cell activity. To the extent that VTA DA cells, in part via their projection to $\mathrm{NAc}$, are involved in modulating the reinforcing responses to nondrug reinforcers decreased DA cell activity could underlie the reduced sensitivity to nonalcohol rewards in alcoholics (Wrase et al., 2007).

\section{Alcohol/nicotine comorbidity}

In alcoholic subjects who were smokers, MP-induced DA changes were correlated with their smoking histories. This association could reflect common adaptation responses to alcohol and tobacco because chronic nicotine also decreases spontaneous activity of VTA DA cells (Liu and Jin, 2004). However, because DA changes did not differ between alcoholic smokers and nonsmokers nor between control smokers and nonsmokers, it is unlikely that the DA reductions were attributable just to smoking but could reflect common vulnerabilities (True et al., 1999; Bierut et al., 2004; Le et al., 2006).

\section{Baseline $\mathrm{DA}_{2} / \mathrm{D}_{3}$ receptor measures}

Baseline DA $D_{2} / D_{3}$ receptor availability was lower in alcoholics than in controls in VS, which corroborates previous imaging

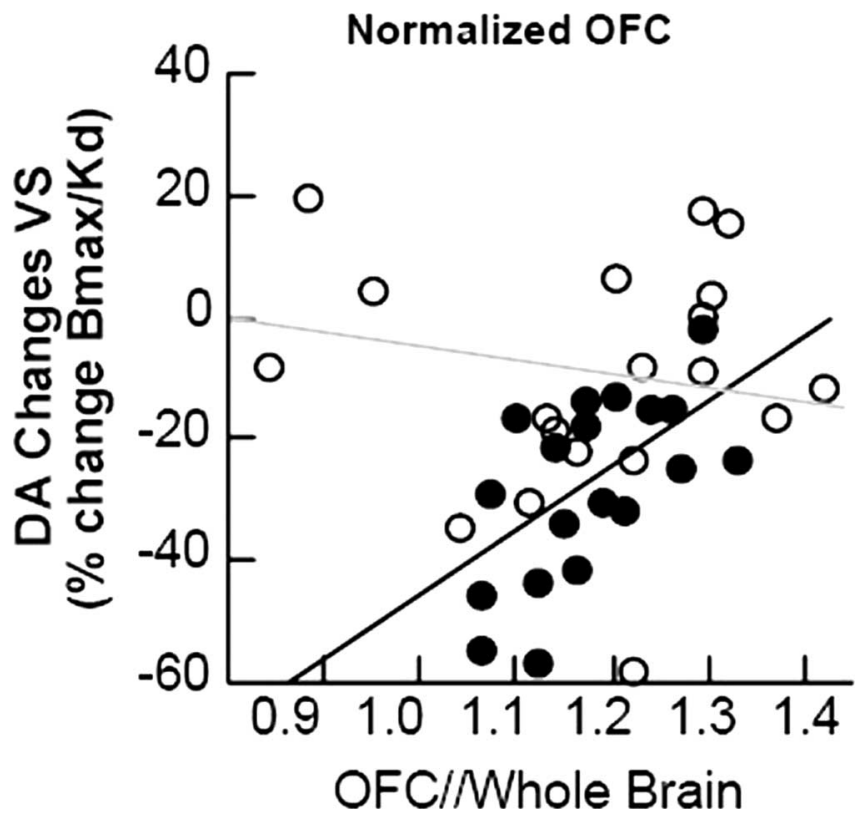

Figure 3. Regression slopes between percentage changes in $B_{\max }{ }^{\prime} / K_{\mathrm{d}}{ }^{\prime}$ (dependent variable) in VS and normalized metabolic activity in OFC (whole brain) in controls (filled circles) and in alcoholics (open circles).

(Heinz et al., 2004; Shen et al., 2007) and postmortem (Tupala et al., 2001, 2003) studies.

Baseline $\mathrm{D}_{2} / \mathrm{D}_{3}$ receptor availability in the alcoholics (but not in controls) was associated with metabolism in CG and DLPFC. This is consistent with previous findings in cocaine and in methamphetamine abusers and in subjects at high genetic risk for alcoholism in whom we also reported an association between baseline striatal $\mathrm{D}_{2} / \mathrm{D}_{3}$ receptor availability and prefrontal metabolism (Volkow et al., 1993b, 2001, 2006). However, it contrasts with the correlations between prefrontal metabolism and MPinduced DA changes, which were significant for controls but not for alcoholics. This is likely to reflect the fact that they correspond to different measures of DA neurotransmission; changes in $B_{\max }{ }^{\prime} / K_{\mathrm{d}}{ }^{\prime}$ reflect DA release from DA neurons, which is a function of DA cell firing and is modulated by prefrontal activity, whereas $D_{2} / D_{3}$ receptor availability mostly reflects receptor levels that presumably are modulated by genetic and epigenetic factors but, to our knowledge, not by prefrontal activity. Thus, the association between baseline $\mathrm{D}_{2} / \mathrm{D}_{3}$ receptors is likely to reflect dopaminergic modulation of prefrontal cortical regions (Oades and 
Halliday, 1987). Indeed, in alcoholics, reductions in D2R availability in VS have been shown to be associated with alcohol craving severity and with greater cue-induced activation of the medial prefrontal cortex and anterior CG as assessed with functional magnetic resonance imaging (Heinz et al., 2004).

\section{Baseline regional brain glucose metabolism}

In this study, we did not show differences in brain glucose metabolism (including frontal cortex) between controls and alcoholics. This differs from previous studies, which have shown reductions in frontal metabolism in alcoholics (for review, see Wang et al., 1998). However, because reductions in brain metabolism recover significantly within 2-4 weeks of detoxification (particularly in frontal cortex) (Volkow et al., 1994b), failure to see reductions in our subjects could reflect the fact that they had withdrawn from alcohol at least $30 \mathrm{~d}$ before the study.

\section{Limitations}

First, because $\left[{ }^{18} \mathrm{~F}\right] \mathrm{FDG}$, has a half-life of $120 \mathrm{~min}$, it was not possible to do the $\left[{ }^{11} \mathrm{C}\right]$ raclopride measures on the same day (10 $\mathrm{h}$ are required between injections). However, because baseline regional brain metabolic measures and measures of MP-induced DA changes are stable when subjects are tested on separate days (Wang et al., 1999a,b), the correlations are likely to have been similar had it been possible to test them on the same day.

Second, the correlations with CG, DLPFC, and insula were not significant when activity was normalized to whole-brain metabolism, so in these regions, the associations should be considered as preliminary. Also, correlations do not necessarily imply causal associations nor do they convey directionality and thus we cannot rule out that the association rather than reflecting prefrontal regulation of DA release reflects DA modulation of prefrontal regions.

Third, reduced baseline $\mathrm{D}_{2} / \mathrm{D}_{3}$ receptor availability when measured with $\left[{ }^{11} \mathrm{C}\right]$ raclopride could reflect either low receptor levels or increased DA release (Gjedde et al. 2005). However, the fact that alcoholics, when given MP, showed reduced DA release indicates that low baseline measures of $\mathrm{D}_{2} / \mathrm{D}_{3}$ receptor availability in the alcoholics reflect, as previously reported by postmortem studies (Tupala et al., 2003), low levels of $\mathrm{D}_{2}$ receptors.

Finally smoking is a confound, but because $\sim 90 \%$ of alcoholics smoke (Batel et al., 1995), our findings are clinically relevant to the majority of alcoholics.

\section{Conclusion}

These results are consistent with the hypothesis of a loss of the prefrontal modulation of DA cell activity in alcoholics and of profound decreases in DA activity in these subjects. The relationship between the blunted DA increase in VS and the reduced rewarding responses to MP suggests that DA abnormalities may underlie the anhedonia experienced by alcoholics and may contribute to their risk for alcohol abuse as a mechanism to compensate for this deficit. These findings suggest that interventions to restore prefrontal regulation and the DA deficit could be therapeutically beneficial in alcoholics.

\section{References}

Bailey CP, Manley SJ, Watson WP, Wonnacott S, Molleman A, Little HJ (1998) Chronic ethanol administration alters activity in ventral tegmental area neurons after cessation of withdrawal hyperexcitability. Brain Res 24:144-152.

Batel P, Pessione F, Maitre C, Rueff B (1995) Relationship between alcohol and tobacco dependencies among alcoholics who smoke. Addiction 90:977-980.
Bierut LJ, Rice JP, Goate A, Hinrichs AL, Saccone NL, Foroud T, Edenberg HJ, Cloninger CR, Begleiter H, Conneally PM, Crowe RR, Hesselbrock V, Li TK, Nurnberger Jr JI, Porjesz B, Schuckit MA, Reich T (2004) A genomic scan for habitual smoking in families of alcoholics: Common and specific genetic factors in substance dependence. Am J Med Genet A 124:19-27.

Carr DB, Sesack SR (2000) Projections from the rat prefrontal cortex to the ventral tegmental area: target specificity in the synaptic associations with mesoaccumbens and mesocortical neurons. J Neurosci 20:3864-3873.

Collins DL, Holmes CJ, Peters TM, Evans AC (1995) Automatic 3-D modelbased neuroanatomical segmentation. Hum Brain Mapp 3:190-208.

Diana M, Pistis M, Carboni S, Gessa GL, Rossetti ZL (1993) Profound decrement of mesolimbic dopaminergic neuronal activity during ethanol withdrawal syndrome in rats electrophysiological and biochemical evidence Proc Natl Acad Sci USA 90:7966-7969.

Diana M, Pistis M, Muntoni A, Gessa G (1996) Mesolimbic dopaminergic reduction outlasts ethanol withdrawal syndrome: evidence of protracted abstinence. Neuroscience 71:411-415.

Fischman MW, Foltin RW (1991) Utility of subjective-effects measurements in assessing abuse liability of drugs in humans. Br J Addict 86:1563-1570.

Gariano RF, Groves PM (1988) Burst firing induced in midbrain dopamine neurons by stimulation of the medial prefrontal and anterior cingulate cortices. Brain Res 462:194-198.

Gaspar P, Berger B, Febvret A, Vigny A, Henry JP (1989) Catecholamine innervation of the human cerebral cortex as revealed by comparative immunohistochemistry of tyrosine hydroxylase and dopamine-betahydroxylase. J Comp Neurol 279:249-271.

Gjedde A, Wong DF, Rosa-Neto P, Cumming P (2005) Mapping neuroreceptors at work: on the definition and interpretation of binding potentials after 20 years of progress. Int Rev Neurobiol 63:1-20.

Hamilton M (1959) The assessment of anxiety states by rating. Br J Med Psychol 32:50-55.

Hamilton M (1960) A rating scale for depression. J Neurol Neurosurg Psychiatry 23:56-62.

Heinz A, Siessmeier T, Wrase J, Hermann D, Klein S, Grusser SM, Flor H, Braus DF, Buchholz HG, Grunder G et al (2004) Correlation between dopamine $\mathrm{D}(2)$ receptors in the ventral striatum and central processing of alcohol cues and craving. Am J Psychiatry 161:1783-1789.

Homayoun H, Moghaddam B (2006) Progression of cellular adaptations in medial prefrontal and orbitofrontal cortex in response to repeated amphetamine. J Neurosci 26:8025-8039.

Jentsch JD, Taylor JR (1999) Impulsivity resulting from frontostriatal dysfunction in drug abuse: implications for the control of behavior by reward-related stimuli. Psychopharmacology (Berl) 146:373-390.

Kalivas PW (2004) Glutamate systems in cocaine addiction. Curr Opin Pharmacol 4:23-29.

Kalivas PW, Volkow ND (2005) The neural basis of addiction: a pathology of motivation and choice. Am J Psychiatry 162:1403-1413.

Koob GF, Roberts AJ, Schulteis G, Parsons LH, Heyser CJ, Hyytia P, MerloPich E, Weiss F (1998) Neurocircuitry targets in ethanol reward and dependence. Alcohol Clin Exp Res 22:3-9.

Lancaster JL, Woldorff MG, Parsons LM, Liotti M, Freitas CS, Rainey L, Kochunov PV, Nickerson D, Mikiten SA, Fox PT (2000) Automated Talairach Atlas labels for functional brain mapping. Hum Brain Mapp 10:120-131.

Le AD, Li Z, Funk D, Shram M, Li TK, Shaham Y (2006) Increased vulnerability to nicotine self-administration and relapse in alcohol-naïve offspring of rats selectively bred for high alcohol intake. J Neurosci 26:1872-1879.

Liu ZH, Jin WQ (2004) Decrease of ventral tegmental area dopamine neuronal activity in nicotine withdrawal rats. NeuroReport 15:1479-1481.

Logan J, Fowler JS, Volkow ND, Wolf AP, Dewey SL, Schlyer DJ, MacGregor RR, Hitzemann R, Bendriem B, Gatley SJ, Christman DR (1990) Graphical analysis of reversible radioligand binding from time-activity measurements applied to [N-11C-methyl]-(-)-cocaine PET studies in human subjects. J Cereb Blood Flow Metab 10:740-747.

Martinez D, Gil R, Slifstein M, Hwang DR, Huang Y, Perez A, Kegeles L, Talbot P, Evans S, Krystal J, Laruelle M, Abi-Dargham A (2005) Alcohol dependence is associated with blunted dopamine transmission in the ventral striatum. Biol Psychiatry 58:779-786. 
Murase S, Grenhoff J, Chouvet G, Gonon FG, Svensson TH (1993) Prefrontal cortex regulates burst firing and transmitter release in rat mesolimbic dopamine neurons studied in vivo. Neurosci Lett 157:53-56.

Naqvi NH, Rudrauf D, Damasio H, Bechara A (2007) Damage to the insula disrupts addiction to cigarette smoking. Science 315:531-534.

Nestler EJ (2004) Molecular mechanisms of drug addiction. Neuropharmacology 47 [Suppl 1]:24-32.

Oades RD, Halliday GM (1987) Ventral tegmental (A10) system: neurobiology. 1. Anatomy and connectivity. Brain Res 434:117-165.

Phelps ME, Huang SC, Hoffman EJ, Selin C, Sokoloff L, Kuhl DE (1979) Tomographic measurement of local cerebral glucose metabolic rate in humans with (F-18)2-fluoro-2-deoxy-D-glucose: validation of method. Ann Neurol 6:371-388.

Robbins TW, Everitt BJ (2002) Limbic-striatal memory systems and drug addiction. Neurobiol Learn Mem 78:625-636.

Shen RY, Choong KC, Thompson AC (2007) Long-term reduction in ventral tegmental area dopamine neuron population activity following repeated stimulant or ethanol treatment. Biol Psychiatry 61:93-100.

Shen WW (1984) Extrapyramidal symptoms associated with alcohol withdrawal. Biol Psychiatry 19:1037-1043.

Sokoloff L, Reivich M, Kennedy C, Des Rosiers MH, Patlak CS, Pettigrew KD, Sakurada O, Shinohara M (1977) The [14C]deoxyglucose method for the measurement of local cerebral glucose utilization: theory, procedure, and normal values in the conscious and anesthetized albino rat. J Neurochem 28:897-916.

True WR, Xian H, Scherrer JF, Madden PA, Bucholz KK, Heath AC, Eisen SA, Lyons MJ, Goldberg J, Tsuang M (1999) Common genetic vulnerability for nicotine and alcohol dependence in men. Arch Gen Psychiatry 56:655-661.

Tupala E, Hall H, Bergstrom K, Sarkioja T, Rasanen P, Mantere T, Callaway J, Hiltunen J, Tiihonen J (2001) Dopamine $\mathrm{D}(2) / \mathrm{D}(3)$-receptor and transporter densities in nucleus accumbens and amygdala of type 1 and 2 alcoholics. Mol Psychiatry 6:261-267.

Tupala E, Hall H, Bergstrom K, Mantere T, Rasanen P Sarkioja T, Tiihonen J (2003) Dopamine D2 receptors and transporters in type 1 and 2 alcoholics measured with human whole hemisphere autoradiography. Hum Brain Mapp 20:91-102.

Volkow ND, Fowler JS, Wang G-J, Dewey SL, Schlyer D, MacGregor R, Logan J, Alexoff D, Shea C, Hitzemann R, Angrist B, Wolf AP (1993a) Reproducibility of repeated measures of carbon-11-raclopride binding in the human brain. J Nucl Med 34:609-613.

Volkow ND, Fowler JS, Wang GJ, Hitzemann R, Logan J, Schlyer DJ, Dewey SL, Wolf AP (1993b) Decreased dopamine D2 receptor availability is associated with reduced frontal metabolism in cocaine abusers. Synapse 14:169-177.

Volkow ND, Wang G-J, Fowler JS, Logan J, Schlyer D, Hitzemann R, Lieberman J, Angrist B, Pappas N, MacGregor R, Burr G, Cooper T, Wolf AP (1994a) Imaging endogenous dopamine competition with [11C]raclopride in the human brain. Synapse 16:255-262.

Volkow ND, Wang G-J, Hitzemann R, Fowler JS, Overall JE, Burr G, Wolf AP (1994b) Recovery of brain glucose metabolism in detoxified alcoholics. Am J Psychiatry 151:178-183.

Volkow ND, Wang G-J, Fowler JS, Logan J, Gatley SJ, Hitzemann R, Chen AD, Dewey SL, Pappas N (1997) Decreased striatal dopaminergic responsiveness in detoxified cocaine-dependent subjects. Nature 386:830-833.

Volkow ND, Wang G-J, Fowler JS, Gatley SJ, Logan J, Ding YS, Hitzemann R, Pappas N (1998) Dopamine transporter occupancies in the human brain induced by therapeutic doses of oral methylphenidate. Am J Psychiatry 155:1325-1331.

Volkow ND, Wang G-J, Fowler JS, Gatley SJ, Logan J, Ding YS, Dewey SL, Hitzemann R, Gifford AN, Pappas NR (1999) Blockade of striatal dopamine transporters by intravenous methylphenidate is not sufficient to induce self-reports of "high." J Pharmacol Exp Ther 288:14-20.

Volkow ND, Chang L, Wang GJ, Fowler JS, Ding YS, Sedler M, Logan J, Franceschi D, Gatley J, Hitzemann R, Gifford A, Wong C, Pappas N (2001) Low level of brain dopamine D2 receptors in methamphetamine abusers: association with metabolism in the orbitofrontal cortex. Am J Psychiatry 158:2015-2021.

Volkow ND, Wang G-J, Fowler JS, Logan J, Franceschi D, Maynard L, Ding YS, Gatley SJ, Gifford A, Zhu W, Swanson JM (2002) Relationship between blockade of dopamine transporters by oral methylphenidate and the increases in extracellular dopamine: therapeutic implications. Synapse 43:181-187.

Volkow ND, Fowler JS, Wang GJ (2003) The addicted human brain: insights from imaging studies. J Clin Invest 111:1444-1451.

Volkow ND, Wang G-J, Begleiter H, Porjesz B, Fowler JS, Telang F, Wong C, Ma Y, Logan J, Goldstein R, Alexoff D, Thanos PK (2006) High levels of dopamine D2 receptors in unaffected members of alcoholic families: possible protective factors. Arch Gen Psychiatry 63:999-1008.

Wang G-J, Volkow ND, Roque CT, Cestaro VL, Hitzemann RJ, Cantos EL, Levy AV, Dhawan AP (1993) Functional importance of ventricular enlargement and cortical atrophy in healthy subjects and alcoholics as assessed with PET, MR imaging, and neuropsychologic testing. Radiology 186:59-65.

Wang G-J, Volkow ND, Hitzemann RJ, Wong C, Angrist B, Burr G, Pascani K, Pappas N, Lu A, Cooper T, Lieberman JA (1997) Behavioral and cardiovascular effects of intravenous methylphenidate in normal subjects and cocaine abusers. Eur Addict Res 3:49-54.

Wang G-J, Volkow ND, Fowler JS, Pappas NR, Wong CT, Pascani K, Felder CA, Hitzemann RJ (1998) Regional cerebral metabolism in female alcoholics of moderate severity does not differ from that of controls. Alcohol Clin Exp Res 22:1850-1854.

Wang GJ, Volkow ND, Levy AV, Felder CA, Fowler JS, Pappas NR, Hitzemann RJ, Wong CT (1999a) Measuring reproducibility of regional brain metabolic responses to lorazepam using statistical parametric maps. J Nucl Med 40:715-720.

Wang GJ, Volkow ND, Fowler JS, Logan J, Pappas NR, Wong CT, Hitzemann RJ, Netusil N (1999b) Reproducibility of repeated measures of endogenous dopamine competition with [11C]raclopride in the human brain in response to methylphenidate. J Nucl Med 40:1285-1291.

Weiss F, Parsons LH, Schulteis G, Hyytiä P, Lorang MT, Bloom FE, Koob GF (1996) Ethanol self-administration restores withdrawal-associated deficiencies in accumbal dopamine and 5-hydroxytryptamine release in dependent rats. J Neurosci 16:3474-3485.

White FJ, Hu XT, Zhang XF, Wolf ME (1995) Repeated administration of cocaine or amphetamine alters neuronal responses to glutamate in the mesoaccumbens dopamine system. J Pharmacol Exp Ther 273:445-454.

Wrase J, Schlagenhauf F, Kienast T, Wustenberg T, Bermpohl F, Kahnt T, Beck A, Strohle A, Juckel G, Knutson B, Heinz A (2007) Dysfunction of reward processing correlates with alcohol craving in detoxified alcoholics. NeuroImage 35:787-794. 